\title{
ARTICLE
}

\section{Why Think for Yourself?}

\author{
Jonathan Matheson (it) \\ University of North Florida, Jacksonville, Florida, USA \\ Email: j.matheson@unf.edu
}

(Received 14 April 2021; revised 12 October 2021; accepted 28 October 2021)

\begin{abstract}
In this paper, I explore an underappreciated tension between two epistemic values: epistemic autonomy and the love of truth. On the one hand, it seems as though any healthy intellectual life includes thinking about a number of issues for oneself. On the other hand, it seems as though taking inquiry seriously requires you to take the best available route to the answer, and typically that is not thinking for yourself. For nearly any question you want to investigate, there is someone who is in a better epistemic position than you are to determine the answer. In what follows, I will first clarify our central question and sharpen this novel puzzle regarding epistemic autonomy. Having done so, I will argue that autonomous deliberation can be epistemically valuable to inquirers both when it is successful, as well as when it is unsuccessful. I conclude by gesturing at how these considerations point us toward an account of epistemic autonomy as an intellectual virtue.
\end{abstract}

\section{Introduction}

Life is a group project. It takes a village. The same is true of our intellectual lives. Since we are finite cognitive creatures with limited time and resources, any healthy intellectual life requires that we rely quite heavily on others. For nearly any question you want to investigate, there is someone who is in a better epistemic position than you are to determine the answer. For most people, their expertise does not extend far beyond their own personal lives, and even here we can sometimes find others who are more reliable. The minds of these intellectual superiors are a great epistemic resource. Without relying on them we would know very little about the world. Since others are typically better positioned to determine the answers to the questions we have, it should make us wonder why we should bother to try and figure out much of anything at all for ourselves. After all, when trying to find an answer to a question, we should take the best available route to the answer, and the most reliable route to the answer to most questions is to rely on the minds of others. At the same time, there is something defective about an intellectual life that outsources nearly all of its intellectual projects, even if the outsourcing is not done out of laziness. A life full of intellectual outsourcing seems defective even if it is motivated by a love for the truth - out of the desire to have true beliefs and to avoid false ones. These are precisely the goals that an epistemic agent ought to have, however, even here something appears to be defective with an intellectual life full of outsourcing. That is, it seems that individuals ought to think for themselves, 
at least about some issues and at least some of the time. The puzzle is in determining why it is epistemically valuable to think for yourself, since doing so will almost always not be the best available route to the answer to your question. ${ }^{1}$

The tension here is between two epistemic values: epistemic autonomy and the love of truth. On the one hand, it seems as though any healthy intellectual life includes thinking about a number of issues for oneself. This is captured by the motto of the enlightenment, 'have courage to use your own reason!' In addition to this, developing epistemic autonomy in students is one of the primary goals of education. ${ }^{2}$ On the other hand, it seems as though taking inquiry seriously requires you to take the best available route to the answer, and typically that is not thinking for yourself. An insistence to do it on one's own, when that is a recognizably less reliable route to the answer looks epistemically defective.

In what follows, I will first clarify our central question and sharpen this puzzle regarding epistemic autonomy. Having done so, I will argue that autonomous deliberation can be epistemically valuable to inquirers both when it is successful, as well as when it is unsuccessful. I conclude by gesturing at how these considerations point us toward an account of epistemic autonomy as an intellectual virtue.

\section{Sharpening the puzzle}

The autonomous person determines the course of their own life (Raz 1988). The epistemically autonomous person exhibits autonomy in their intellectual life. This can happen in a number of ways. First, epistemically autonomous people determine which intellectual projects they take on. They are not coerced or manipulated into conducting any particular inquiry, but are autonomous in terms of which questions they investigate. Epistemically autonomous people shape their own intellectual lives. ${ }^{3}$ We can call this aspect of epistemic autonomy 'autonomy in inquiry selection'. Second, individuals can be epistemically autonomous with respect to how they conduct their inquiry into any given question; they can be more or less autonomous with respect to their level of involvement in their inquiry. Epistemically autonomous people don't merely take someone else's word as establishing the answer to their question, but rather, they want to see the relevant reasons for themselves and they want to evaluate those reasons for themselves. Sandy Goldberg puts it as follows,

an epistemically autonomous subject is one who judges and decides for herself, where her judgments and decisions are reached on the basis of reasons which she has in her possession, where she appreciates the significance of these reasons, and where (if queried) she could articulate the bearing of her reasons on the judgment or decision in question. (Goldberg 2013: 169)

We can call this aspect of epistemic autonomy 'autonomy in deliberation', since agents who are autonomous in this way opt for deliberation over mere deference. Autonomous deliberators handle the information for themselves rather than merely taking someone

\footnotetext{
${ }^{1}$ In some sense, this question and puzzle are an extension of the puzzle of moral deference. The puzzle of moral deference concerns what, if anything, is amiss about merely deferring on some moral matter. While there is a significant literature on this puzzle, its extension to non-moral moral matters has not been adequately appreciated. See McGrath (2009) for a discussion of the puzzle of moral deference.

${ }^{2}$ See Ebels-Duggan (2014) and Nussbaum (2017).

${ }^{3}$ See Coady (2002).
} 
else's word for it. Our concern, here, is with this latter aspect of epistemic autonomy with how individuals go about their inquiry into a particular question.

It is important to note that autonomous deliberation does not require one to entirely forego the intellectual resources of others. The autonomous deliberator need not be an intellectual maverick who does everything on their own. Epistemic autonomy must be understood within the context of a broader social epistemology. As King (2020: 55) nicely expresses this thought, "autonomy requires thinking for ourselves, not by ourselves". This is important since the independent epistemic life looks impoverished if not impossible. We routinely rely on others for language, ideas, information, as well as a number of other epistemic tools. In addition, we rely on others to develop our skills in using these tools. None of this is in conflict with autonomous deliberation. We must rely on others for our own cognitive development. In fact, autonomy seems to require that we occupy certain social relations. ${ }^{5}$ As Grasswick (2018: 201) argues, without the right kind of personal relations and a nurturing epistemic environment, one's development of epistemic autonomy is actually significantly threatened. ${ }^{6}$ Beyond its development, autonomous deliberation itself requires that we engage with others. Autonomous deliberation requires that we consider different perspectives and the ways in which others would respond to our reasoning. Epistemically autonomous individuals see themselves as answerable to others and as accountable for their reasoning. ${ }^{7}$ Such autonomy is essentially relational and interpersonal.

So, the contrary to autonomous deliberation is mere deference, not dependence. When an individual merely defers to someone else on some proposition, that individual takes on their belief solely on the testifier's say-so. ${ }^{8}$ So, when an individual merely defers to another, she does not engage the relevant reasons for herself, ${ }^{9}$ she simply takes the speaker's word for it and relies on their evidence and their evaluation of it. Autonomous deliberation requires getting the relevant first-order ${ }^{10}$ reasons for oneself, and evaluating them for oneself, but this can be done while still relying heavily on others. For instance, others can supply us with the first-order reasons, and others can equip us to evaluate those reasons. ${ }^{11}$

We should also distinguish between two types of questions about which one may inquire. There are first-order questions and higher-order questions. ${ }^{12}$ First-order

\footnotetext{
${ }^{4}$ See also Encabo (2008).

${ }^{5}$ See Nedelsky (1989), Encabo (2008), and Grasswick (2018). Zagzebski (2012) also argues that epistemic autonomy is incompatible with self-reliance.

${ }^{6}$ See Medina (2012) for an argument regarding how one's social position affects the development of their cognitive character (both virtuous and vicious).

${ }^{7}$ See Westlund (2012), Elgin (2013), and Grasswick (2018).

${ }^{8}$ See Fricker (2006) and McGrath (2009).

${ }^{9}$ This is not to say that the deferring individual cannot have reasons to trust the person to whom she is deferring. Having reason to trust a speaker is not incompatible with deference. Such reasons are higherorder evidence in that they are reasons about the quantity and quality of the speaker's evidence as well as their reliability in evaluating that evidence.

${ }^{10} \mathrm{~A}$ helpful distinction is between first-order evidence and higher-order evidence. First-order evidence for $\mathrm{p}$ pertains directly to $\mathrm{p}$, whereas higher-order evidence concerning $\mathrm{p}$ directly pertains to the evidence relevant to $\mathrm{p}$. When a speaker testifies that $\mathrm{p}$, they give the hearer higher-order evidence. In particular, the speaker gives the hearer evidence that the speaker's evidence supports $\mathrm{p}$, without necessarily also giving the hearer those first-order reasons.

${ }^{11}$ Autonomous deliberation can also happen alongside deference (though not alongside mere deference). An individual can rely on another for the answer to a question and also think through the issue for themself. More on this later.

${ }^{12}$ This parallels the distinction between first-order evidence and higher-order evidence.
} 
questions directly pertain to some matter. The following are all examples of first-order questions:

- Is there anthropogenic climate change?

- Will lowering the federal interest rate help boost the economy?

- Is it morally permissible to eat meat?

In contrast, higher-order questions are questions about other questions. The higherorder questions of particular concern here, are questions about who to trust regarding the answers to other questions. The following are all examples of such higher-order questions:

- Whom should I trust about determining whether there is anthropogenic climate change?

- Whom should I trust about determining whether lowering the interest rate will help boost the economy?

- Whom should I trust about determining whether it is morally permissible to eat meat? ${ }^{13}$

Individuals can exhibit autonomous deliberation with respect to both first-order questions and higher-order questions. ${ }^{14}$ There are important and complicated issues regarding autonomous deliberation about higher-order questions. Perhaps of utmost importance is the question, 'how can a novice about some field identify experts in that field?' Much has been said about this question and potential answers to it. ${ }^{15}$ However, our focus here is autonomous deliberation with respect to first-order questions. ${ }^{16}$ Our question, is when should someone think about a question, q, for themselves? If they decide that they should not think about $q$ for themselves (while wanting to have an opinion on the matter), then they will have to confront the higher-order question of whom to trust about q, or who to trust about who to trust about q, and so forth. While those higher-order questions may not have easy and straightforward answers, they are not our focus here.

We also need to distinguish two groups of inquirers regarding questions in some domain: experts and novices. Experts in a domain are those individuals who are the most likely to be correct regarding the questions in that domain. Experts in a domain have the most robust bodies of evidence relevant to questions in that domain and they are the most capable of evaluating that evidence. We can think of experts in a domain as the epistemic authorities in that domain. In contrast, the novices in a domain are those that are not experts in that domain. ${ }^{17}$ Novices may lack expertise due to a lack of critical

\footnotetext{
${ }^{13}$ There are also higher-order questions such as 'whom do I trust in determining whom do I trust about determining whether it is morally permissible to eat meat?' and so forth.

${ }^{14}$ Nguyen (2018) refers to autonomy with respect to what I am calling 'higher-order questions' as 'meta-autonomy'.

${ }^{15}$ See Goldman (2001) for the central statement of the puzzle. For discussion, see Kitcher (1993), Coady (2002), Cholbi (2007), Collins and Evans (2007), Lane (2014), Millgram (2015), Dellsén (2018), Matheson et al. (2018), and Nguyen (2020).

${ }^{16}$ It's not a competition, but Huemer (2005) maintains that the first-order questions are more difficult. To motivate this, he notes that we feel the need to rely on expert testimony regarding first-order questions in trials, but do not feel the need to rely on expert testimony regarding who the relevant experts are. This, he takes it, shows that we find it easier to identify the relevant experts about $p$, than to determine $p$ itself.

${ }^{17}$ Being an expert, and being a novice, admit of degrees. For simplification, we will ignore those complications here.
} 
pieces of evidence relevant to that domain or due to an inability to adequately evaluate that evidence. In the cognitive division of labor, the novices in a domain rely on the experts in that domain to figure out the truth of the matter. Here, our concern is with novices in a domain, and why they should bother to think about questions in that domain for themselves. ${ }^{18}$

There can be all kinds of reasons why it might be good to think for yourself. If it is good to fulfill your desires and you desire to think through some question for yourself, then doing so is a good thing for you to do. Thinking for yourself could have practical value, social value, ${ }^{19}$ and it may even have moral value. However, the kind of value that concerns us here is epistemic value. Is thinking for yourself epistemically valuable? Epistemic value is the kind of value that attaches to various kinds of cognitive successes: true belief, justified belief, knowledge, understanding, intellectual virtue, and so forth. It is the value that something has from the epistemic perspective - from the perspective of wanting to believe truths and to avoid false beliefs. So, apart from your desires and what makes you happy, is it intellectually valuable to think for yourself?

With all of these distinctions in hand, we can put our central question as follows:

\section{Q: Is it epistemically valuable for a novice about some domain to autonomously} deliberate about a first-order question in that domain?

There are some situations where you simply have to think for yourself. In some situations, you lack the time or the resources to consult expert opinion. That is, in some cases, you need to form a belief quickly, and practical constraints require that you think for yourself. In such cases the epistemically best option is for you to think about the matter for yourself. In other cases, there simply may be no experts to turn to. Some domains may lack experts and some questions may be so novel that everyone else has yet to contemplate them. Here too, deference may simply not be an option. Finally, in some cases there may be experts, but novices may be unable to identify who the relevant experts are. That is, in some domains, the experts may operate on what Nguyen (2018) calls 'cognitive islands'. To identify experts on cognitive islands, you cannot use some litmus test ${ }^{20}$ or indirect calibration ${ }^{21}$ to identify the experts in that domain. Rather, to identify an expert on a cognitive island, you need to yourself be an expert in that domain. As Millgram (2015: 45) puts the idea, "in order to apply the standards of the _ologists, you have to be a _ologist yourself". If we cannot determine who the experts are, then we cannot rationally defer to the experts even if they exist. Here too, thinking for oneself seems to be the only option.

However, the cases that concern us here, are cases where deference to the experts is a live option. So, the cases that concern us here are cases where one has the time and ability to identify the relevant experts, as well as how they answer the target question. Such cases best illustrate the tension between epistemic autonomy and the love of truth.

\footnotetext{
${ }^{18}$ For arguments as to why it is epistemically valuable for the experts in a domain to be epistemically autonomous (in this sense), see Dellsén (2020, 2021).

${ }^{19}$ See Hazlett (2016) for several arguments that epistemically autonomous deliberation has social value (at least in some cases). While Hazlett's stated focus is on the social value of autonomous deliberation, his argument from collective reliability also has epistemic consequences. Thanks to an anonymous referee for this point.

${ }^{20}$ Some empirical fields admit of a litmus test which allows us to validate the expertise of practitioners in that field. See Nguyen (2020).

${ }^{21}$ Some fields overlap with other fields, and recognized experts in those overlapping fields can help identify the experts in the target field. See Kitcher (1993) in addition to Nguyen (2020).
} 
When you have the option to defer to the experts, an epistemically good option, then why think about the issue for yourself ? $^{22}$

In terms of epistemic value, it is clearly epistemically valuable for an individual to believe truths and not believe falsehoods. So, what creates the tension here is that it is clearly epistemically valuable to defer to experts regarding questions in their domain of expertise. Relying on the relevant experts is a reliable way to find answers to our questions. In fact, it is a much more reliable route to the answers than novice autonomous deliberation. This makes it hard to see what epistemic value there could be in novice autonomous deliberation, particularly when deference to the experts is a live option.

One final clarification regarding deference to the experts is in order. The state of expert opinion on some question can either be in a state of consensus or a state of disarray. ${ }^{23}$ A state of consensus obtains when there is a clear majority agreement amongst the relevant experts. A state of disarray obtains when there is no clear dominant view amongst the experts. In a state of disarray, there is widespread disagreement amongst the relevant experts. When the state of expert opinion regarding some question is in a state of consensus, then deferring to the experts amounts to believing the consensus answer. When the state of expert opinion regarding some question is in a state of disarray, then, as I am using the phrase, 'deferring to the experts' amounts to not believing any particular answer to the question. In a sense, you are deferring to the disarray and abstaining from believing any particular answer to your question. So, to defer to the experts is to believe the consensus answer when there is one, and to not believe any particular answer when there is no consensus.

So, the final formulation of our question is as follows:

Q': Is it epistemically valuable for a novice about some domain to autonomously deliberate about a first-order question in that domain when they could merely defer to the experts in that domain?

Before turning to our answer, let's sharpen the puzzle by first seeing why a 'yes' answer to our question is challenging. Consider the following cases:

\section{Case 1}

On his morning commute, Stan is listening to his favorite sports talk radio show. He hears that even if Wayne Gretzky did not score any of his record 894 goals, he would still be the NHL point leader in virtue of all of his assists. Stan is amazed but believes the statistic. While Stan might look it up later (to verify with other expert opinions), it would be silly for Stan to go gather all of the relevant box scores for himself to determine whether the stat is correct. ${ }^{24}$ While that is one way for Stan to live his life, epistemically speaking, it would be a waste of his time. Since he has credible testimony, truth, justification, and knowledge are all his for the taking without these efforts. Thinking for himself on the matter would be waste. If anything, Stan is likely to make an error in counting and be led away from the truth.

\footnotetext{
${ }^{22}$ One might worry at this point that the value in epistemic autonomy is exhausted by the types of cases that we are setting aside. However, as we will see, there is good reason to see autonomous deliberation as epistemically valuable even in this narrower subset of cases.

${ }^{23}$ See Matheson et al. (2018).

${ }^{24}$ Note that this would not only involve the box scores for all of Gretzky's games, but also the box scores of all of the games where other players played.
} 


\section{Case 2}

Luna has recently become very interested in nutrition. Recently, she has been studying caffeine and its effects on the body. In her inquiry, Luna consults her chemist friend Cora who tells her, among other things, that caffeine has the molecular formula $\mathrm{C} 8 \mathrm{H} 10 \mathrm{~N} 402$. This is new information to Luna, but Luna knows that Cora knows her stuff. Instead of simply taking Cora's word for it, Luna could try and figure out the molecular formula of caffeine for herself. All she would need to do is find the molar mass of the compound, divide it by the empirical formula mass, and so forth. However, Luna recognizes that she is far more likely to bungle these measurements and calculations than she is to do it all correctly. If anything, thinking for herself here would only lead her away from the answer that she has by way of Cora.

In each case, the subject's 'thinking for themselves' looks to be either a waste or epistemically dangerous. That is, in each case, it seems that autonomous deliberation is not going to improve the subject's epistemic position regarding the answer to their question, and, if anything, it will actually worsen it. In sorting through the evidence for themselves, the novice is only more likely to bungle things resulting in them being moved away from the truth. This makes it hard to see what epistemic value there could be in such autonomous deliberation.

Consider an analogy to help see how this worry generalizes. Suppose that you have a goal of making a fancy dessert. You have two options. First, you can try and follow the complicated recipe yourself, but you are an amateur baker at best. Second, Martha Stewart is at hand and is happy to do the baking for you. With the goal of getting the dessert right, it is clear that you should turn the project over to Martha. If the dessert is something that she can do, then you are far more likely to get a good result in having Martha make the dessert. If the dessert is too complicated for even Martha to make, then you are still better off giving her a crack at it. If either of you are going to succeed, it is Martha. Further, so long as Martha is giving it a go, your odds of getting a successful dessert do not increase in any significant way if you also attempt the dessert. Your additional efforts will be a waste, and if anything, you'll just get in her way and make success less likely. Trying it for yourself looks like it's either unhelpful or problematic.

In inquiry, you have the goal of finding the answer to a question. There are several ways you can go about this. You can think for yourself (autonomous deliberation) or you can defer to the experts. If the experts can figure it out, then their answer is the one to go with. You should adopt their answer. If the experts can't figure it out, then your novice inquiry looks futile. If anyone is going to find the answer to a question, it is the experts in that domain. So, novice autonomous deliberation never seems like the way to go, at least epistemically speaking. You may want to engage in the inquiry for the fun of it, just like you may take on the baking project just for the fun of it, but insofar as the goal is getting it right, leaving things to the experts looks like the way to go. Sometimes it is important to trust others and lean not on our own understanding. Hardwig (1985) puts the point this way,

Within her area of expertise, an expert's opinion is better than a non-expert opinion. By "better," I mean more reliable. ... Areas in which expert opinion exists and is available are areas in which one ought not to make up one's own mind - without first becoming an expert. (Hardwig 1985: 84-5) 
These considerations put significant pressure on the idea that autonomous deliberation is epistemically worthwhile, at least in the situations that concern us here. ${ }^{25}$

\section{The options}

The epistemic value of autonomous deliberation about some question, q, could be located in any of four different places. Autonomous deliberation could be:

(i) valuable for the individual, with respect to the target question $\mathrm{q}$.

(ii) valuable for the individual, with respect to some other question, q'

(iii) valuable for a larger group, with respect to the target question $\mathrm{q}$.

(iv) valuable for a larger group, with respect to some other question, q'.

Autonomous deliberation about some question by experts in that domain has clear epistemic value for society. ${ }^{26}$ Society at large relies on experts to find answers to questions in their respective fields, and the most reliable way to determine those answers is to have autonomous deliberation amongst the relevant experts. However, it's harder to see how autonomous deliberation by a novice could have epistemic value for some larger group, particularly when there is already expert opinion to defer to on the matter. If there is consensus amongst the relevant experts that anthropogenic climate change is real, then having novice Norman also look into the matter will likely not improve society's epistemic position on the topic. It is already reasonable to defer to the experts, and Norman's inquiry is unlikely to change that in any significant way. Similarly, if there is widespread disagreement amongst the relevant experts that eating meat is morally permissible, then having novice Norman also look into the matter is likely not going to improve society's epistemic position on this matter either. If those who are in the best epistemic position on the matter can't figure it out, then the rational thing for us to do is to suspend judgment. ${ }^{27}$ Norman's autonomous deliberation about the matter is unlikely to change that. Even if it is important that there be some sort of a check on the relevant experts, it is harder to see that any one individual, particularly a novice, will provide such a benefit to society. ${ }^{28}$ So, the more promising source of epistemic value for novice autonomous deliberation lies with the individual inquirer.

While others may be less pessimistic about the prospects of value of types (iii) and (iv), my focus in what follows will be on the value of autonomous inquiry for the individual inquirer. To best determine the epistemic value of autonomous deliberation for novices, we should examine the various ways that such deliberation might play out.

\section{The good case}

In the good case, a novice thinks about some question for themselves and comes to see the answer for themselves. Here is an example:

\section{Dana and DeMorgan's}

Dana is an undergraduate logic student. So far, she has done pretty well in the course, but the class has just gotten to the Replacement Rules and she is struggling.

\footnotetext{
${ }^{25}$ These concerns are also motivated in Huemer (2005), Levy (2007), Zagzebski (2012), and Grundmann (2021).

${ }^{26}$ See Dellsén $(2020,2021)$.

${ }^{27}$ For a more detailed argument for this conclusion, see Matheson (2015).

${ }^{28} \mathrm{After}$ all, there remain different bodies of experts, different degrees of expertise, and so forth.
} 
Her professor has told her that DeMorgan's is a truth-preserving rule, and she believes her professor, but she still doesn't see it for herself. When she asks her professor why DeMorgan's is truth-preserving, her professor explains that the two statement forms are logically equivalent. Dana believes her professor about this as well. After all, it's very unlikely that her professor and her text are both wrong about this. One night, after thinking things through some more on her own, Dana sees it. She now grasps that the relevant statement forms are logically equivalent, and that the rule is truth preserving.

Now that she sees it for herself, Dana is in a better epistemic position with respect to DeMorgan's being a truth-preserving rule. She didn't need to autonomously deliberate about the matter to get either a true belief, a justified belief, or even knowledge. She could have had all of these epistemically valuable states through mere deference to her professor. What Dana did gain is understanding and understanding has epistemic value over and above knowledge. ${ }^{29}$ As Hazlett (2016) puts it,

Even when some proposition is well supported by testimonial evidence, many people still want to understand the (non-testimonial) argument that supports it, to grasp the (non-testimonial) evidence for it, or to see it for themselves. (Hazlett 2016: 131)

So, in the good case, individuals gain something of epistemic value, relative the very question at hand - they understand the answer to their question and see it for themselves. This is an epistemically valuable cognitive achievement. ${ }^{30}$

This connection between understanding and epistemic autonomy has been recognized by many particularly in the context of moral testimony. ${ }^{31}$ Unlike knowledge, understanding cannot be gained by mere deference. ${ }^{32}$ Understanding must be achieved by the inquirer. Zagzebski expresses this thought as follows,

Autonomy may be necessary in the quest for understanding, not because there is something allegedly better about the autonomous understander over the nonautonomous understander, but because we can only get understanding on our own. (Zagzebski 2007: 260)

And elsewhere,

understanding cannot be given to another person at all except in the indirect sense that a good teacher can sometimes recreate the conditions that produce understanding in hopes that the student will acquire it also. (Zagzebski 2008: 146)

\footnotetext{
${ }^{29}$ See Kvanvig (2003), de Regt (2009), Pritchard (2009), Grimm (2010), Gardiner (2012), and Elgin (2017) for discussions of the epistemic value of understanding.

${ }^{30}$ See Pritchard (2016) for an extended argument for the epistemic value of 'seeing it for oneself. Pritchard argues that such a state demonstrates a 'strong cognitive achievement' and is the ultimate goal of inquiry.

${ }^{31}$ Nickel (2001), Zagzebski (2007, 2012: 175-6), Hills (2009, 2013), Roberts and Wood (2010), Hazlett (2016), and Nguyen (2018) are some examples.

${ }^{32}$ See Zagzebski (2008).
} 
Hills, focused on moral understanding, expresses this same sentiment as follows:

If you understand why $\mathrm{X}$ is morally right or wrong, you must have some appreciation of the reasons why it is wrong. Appreciating the reasons why it is wrong is not the same as simply believing that they are the reasons why it is wrong, or even knowing that they are the reasons why it is wrong. Moral understanding involves a grasp of the relation between a moral proposition and the reasons why it is true. (Hills 2009: 101)

So, the autonomous deliberator not only possesses the answer to her question, she grasps the reasons why it is true - she understands the answer. ${ }^{33,34}$

In addition to understanding, the successful autonomous deliberator is in a better position to manage incoming defeaters and adapt to new evidence more generally on the issue. ${ }^{35}$ If an individual does not possess the relevant first-order evidence, then when she comes to possess higher-order evidence that speaks to the import of that firstorder evidence, she will not know whether, or how, to manage her belief accordingly. Further, if she gains some first-order evidence, she will not be able to determine whether her current belief already takes this first-order evidence into account (indirectly), or whether it calls for doxastic modification on her part. Successful autonomous deliberators can avoid these problems by possessing and appreciating the relevant firstorder evidence for themselves.

For instance, suppose that Bill believes that butter is healthier than margarine, but only on the basis of testimony from a reliable source. Suppose that the source's evidence for this claim is a series of studies that all came to this conclusion. However, suppose that it comes to light that these studies are part of a set of studies that are now known to be seriously flawed. If Bill finds out that there is this set of studies that have been found to be seriously flawed, while unaware that his belief that butter is healthier than margarine is indirectly supported (through testimony) by these studies, then Bill will be unable to assess the relevance of this new evidence to his butter belief. In contrast, if Bill, in addition to taking on his testimonial belief, autonomously deliberated about the matter, then he would (or at least could) become aware of the relevance of this new evidence. Being in possession of the relevant first-order evidence enables one to reevaluate the target proposition in light of new evidence, at least in ways that are unavailable to someone who has merely deferred.

Alternatively, if Bill learns about a study that indicates that butter is healthier than margarine but is unaware of whether his source was aware of this study, Bill will not know how to adjust his belief/confidence in light of this evidence. In contrast, if Bill is aware of his source's reasons, then he will know whether this study is new evidence or whether it has already been accounted for. So, autonomous deliberation also has the

\footnotetext{
${ }^{33}$ There are perhaps two types of understanding that are relevant here. Propositional understanding concerns understanding that something is the case. See Kvanvig (2003) for a discussion. Understanding-why, or explanatory understanding, concerns understanding why something is the case. Hills, for instance, is explicitly concerned with understanding-why, but both types of understanding are on the table in good cases of autonomous deliberation. How propositional understanding and understanding-why are related, and whether they are in fact distinct, are themselves philosophical issues. For a discussion, see Gordon (2012). Thanks to an anonymous referee for noting the connections here to these types of understanding discussed in the literature on understanding.

${ }^{34}$ This relationship between epistemic autonomy and understanding is not without its dissenters. See Boyd (2017) for an argument that at least some kinds of understanding can come by way of testimony. See Dellsén (2018) for an argument that an individual can understand without being epistemic autonomous.

${ }^{35}$ See Nickel (2001), Fricker (2006: 242), Nguyen (2020), and Goldberg (2021) for more on this point.
} 
epistemic advantage of potentially equipping inquirers to better manage new information related to the target question. This is value of type (i) above. ${ }^{36}$

\section{The bad case(s)}

Unfortunately, autonomous deliberation does not always work out (particularly for novices), and whether it will work out is not always clear from the outset. However, what has not been adequately appreciated in the literature is that even when autonomous deliberation is unsuccessful, there can be epistemic benefits for the inquirer. There are several distinct types of bad cases worth mentioning. In bad cases of the first type, an individual autonomously deliberates about some question but fails to gain understanding even though it was there to be had. In such a case, the individual gathers the relevant evidence but fails to appreciate it and see why it supports the answer that it in fact supports. Consider the following case:

\section{Carl and Climate Change}

Carl knows that the consensus amongst climate scientists is that anthropogenic climate change is real. The topic really interests him, and he wants to better understand. So, he gathers a number of key books and papers and slowly works his way through them. Unfortunately, Carl is not very good at statistics and in weighing through the data for himself he can't come to see how the evidence supports that there is anthropogenic climate change, though he still believes that there is on the basis of the consensus expert opinion.

Carl fails to gain an understanding of the answer in the way that made Dana's autonomous deliberation epistemically valuable.

A second type of bad case occurs when widespread disagreement amongst the relevant experts (state of disarray) prevents autonomous novice deliberators from even coming to a justified belief about the matter. Consider the following case:

\section{Pam and Personal Identity}

Pam is an undergraduate philosophy major enrolled in Introduction to Metaphysics. The class has just come to the problem of personal identity. Pam is intrigued by the course readings and discussion and continues to look at the debate all through the next summer. It seems to Pam that personal identity has to do with an individual's psychological states, but Pam remembers that her Metaphysics professor noted how deeply divided the issue remains to be among professional philosophers.

Pam's awareness of the widespread disagreement amongst the relevant experts prevents her from being justified in believing her answer to the question of personal identity. In fact, knowing of the controversy ahead of time, Pam could have determined that her inquiry was not going to produce an answer she could be rational in holding. After all, if the greatest minds haven't been able to collectively figure out the answer

\footnotetext{
${ }^{36}$ This benefit is, of course, not guaranteed. It could be that the new information is sufficiently complex, in which case the autonomous deliberator may not be able to appreciate its import even when she possesses the relevant first-order reasons. However, the only chance for such a benefit is if the inquirer also possesses the relevant first-order evidence for herself.
} 
to this question, how could Pam? Furthermore, she's just a beginner. Being aware of the widespread expert controversy prior to her inquiry equips her with a defeater for any justification she might gain for believing any answer to her question that she arrives at in her inquiry. ${ }^{37}$

In both types of bad cases, our subject does not emerge from autonomous deliberation understanding the answer to their question. In Carl's case, a justified belief, and knowledge are on the table, but only because he can still defer to a consensus view amongst the relevant experts. In Pam's case, the widespread disagreement prevents her from even attaining these epistemic goodies with respect to the target proposition.

However, all is not lost for Carl and Pam, even epistemically speaking. For one thing, autonomous novice deliberators can emerge from inquiry understanding the debate even if they fail to understand the answer to their question. Even if Carl and Pam are unable to grasp the answers to their respective questions, they can appreciate the options and the kinds of considerations advanced in favor of different options. That is, failed autonomous deliberation can result in inquirers understanding (or at least better understanding) the intellectual 'lay of the land' - seeing what conceptual space exists and the types of considerations relevant to the debate. Such an understanding of the debate is an epistemic improvement, even if it does not result in the inquirer understanding the answer to the target question. ${ }^{38}$

For instance, even though Pam cannot figure out what makes a person ane time the same person as a person at another time, having autonomously deliberated about the matter, Pam is now aware of the relevant arguments, objections, and thought experiments that are central to that debate. Pam better understands the debate about personal identity even though her inquiry has in some sense been unsuccessful. If Pam had instead merely discovered that the issue was contentious and decided to spend her time doing something else instead, she would be in a worse epistemic position with respect to the debate about personal identity. ${ }^{39}$ This is epistemic value of type (ii) above. ${ }^{40,41}$

In addition to gaining an understanding of the debate, failed autonomous deliberation can have unintended successful consequences. The path of inquiry is winding, not straight, and sometimes it leads to an unintended destination. That is, when inquiry into question $\mathrm{q}$ has been unsuccessful, it sometimes leads to discoveries regarding other

\footnotetext{
${ }^{37}$ One might question whether there are philosophical experts. For discussion, see Goldman (2001), Coady (2002), and Fumerton (2010). However, even if there are not philosophical experts, the fact that a proposition is sufficiently controversial amongst the best candidates for philosophical expertise has a similar defeating effect. If those of us who are best positioned (epistemically speaking) to answer some question cannot do so with any type of consensus, then a rational answer is unavailable to the novice.

${ }^{38}$ What I have here called 'understanding the debate' is a type of understanding that has been called 'objectual understanding.' See Grimm (2011), for discussion. The object of objectual understanding is some subject matter. In this case, the subject matter is the relevant debate or the issue at hand. Objectual understanding can be contrasted with understanding-why and propositional understanding. See note 34 . Thanks again to an anonymous referee for noting the connections here to these types of understanding discussed in the literature.

${ }^{39}$ This is not to say that she would be worse off epistemically altogether. It could be that there would have been greater epistemic benefits in Pam conducting some other inquiry instead. The point here is only that unsuccessful autonomous inquiry is not without its epistemic advantages.

${ }^{40}$ In coming to understand the debate, one comes to understand the answers to questions like the following: What are the core issues here? Who are the central figures? What type of considerations get advanced in favor of this position?

${ }^{41}$ An additional benefit of coming to understand a debate, even when one has not come to understand the answer, is that they are now in a better position to identify who the relevant experts are. In the cases that concern us here, we are assuming that the subjects can identify the relevant experts, but that is often not the case.
} 
questions. While such inquiry has not led to an answer regarding q, it can lead to an answer regarding some other question, q'. Scientific development is full of stories where an individual set out to solve one problem and ended up solving some other problem. ${ }^{42}$ Such unintended success stories can obtain in our intellectual endeavors more generally as well. In inquiring into a question, we may find an answer to some other question, some novel way to approach some other question, some insight that aids us in answering another question, and so forth. So, even when inquiry is unsuccessful with respect to its intended target, it sometimes results in a different, and unforeseen, epistemic success. This too is epistemic value of type (ii) above.

Finally, failed autonomous deliberation can help develop intellectual virtues in inquirers. Following Baehr (2011: 102), I am understanding an intellectual virtue as "a character trait that contributes to its possessor's personal intellectual worth on account of its involving a positive psychological orientation toward epistemic goods." Intellectual virtues are epistemically valuable character traits. So, insofar as failed autonomous deliberation cultivates intellectual virtues, it too will be epistemically valuable. It seems that autonomous deliberation can cultivate open-mindedness, intellectual perseverance, and curiosity, but in what follows, I will focus on the intellectual virtue of intellectual humility.

According to Whitcomb et al. (2017), intellectual humility consists in being appropriately attentive to, and owning, one's intellectual limitations. On this view,

owning one's intellectual limitations characteristically involves dispositions to: (1) believe that one has them; and to believe that their negative outcomes are due to them; (2) to admit or acknowledge them; (3) to care about them and take them seriously; and (4) to feel regret or dismay, but not hostility, about them. (Whitcomb et al. 2017: 519)

Intellectual humility is an intellectual virtue, when this appreciating and owning of one's limitations is motivated by the subject's desire for epistemic goods (e.g. truth, knowledge, understanding, etc.) (Whitcomb et al. 2017: 520).

Such an account of intellectual humility makes evident how failed autonomous deliberation can foster intellectual humility. In failed autonomous deliberations, one's intellectual shortcomings can be made manifest. Failed autonomous deliberation makes it clear that you cannot figure this question out on your own. Such failures do not automatically make an individual intellectually humble, but they are fertile soil for the cultivation of this virtue. If someone only engaged in successful autonomous inquiry it would be very hard for them to be intellectually humble.

So, even failed autonomous deliberation can be epistemically valuable, since it can cultivate intellectual humility, and intellectual humility is epistemically valuable. Intellectual humility, at least when motivated by a desire for epistemic goods, is an intellectual virtue - it is an epistemically good way for an individual to be. Virtuous intellectual character is epistemically valuable in its own right, ${ }^{43}$ but it is also valuable for being utilized by the epistemic agent in their inquiry into other questions. While your inquiry regarding q may have failed, having cultivated your intellectual character,

\footnotetext{
${ }^{42}$ Accidental scientific discoveries include penicillin, microwaves, Velcro, Teflon, vulcanized rubber, and radioactivity among many others.

${ }^{43}$ It is worth pointing out that the intrinsic value of an intellectual virtue is yet another type of epistemic value that goes beyond its instrumental value of type (ii). Thanks to an anonymous reviewer for this clarification.
} 
you are more likely to have successful inquiry into other questions. This too is value of type (ii) above. ${ }^{44,45}$

Bertrand Russell takes this thought even farther. He argues that if you become a more intellectually virtuous person, then society more broadly benefits from having members with better intellectual character. Russell (2016) puts it as follows:

Physical science, through the medium of inventions, is useful to innumerable people who are wholly ignorant of it; thus the study of physical science is to be recommended, not only, or primarily, because of the effect on the student, but rather because of the effect on mankind in general. Thus utility does not belong to philosophy. If the study of philosophy has any value at all for others than students of philosophy, it must be only indirectly, through its effects upon the lives of those who study it. It is in these effects, therefore, if anywhere, that the value of philosophy must be primarily sought. (Russell 2016: 109)

What Russell identifies is that the primary value of studying philosophy, a field of questions where the answers are notoriously hard to come by, is in developing the intellectual character of the inquirer. We have seen above how failed autonomous inquiry can do this. In addition, Russell shows us how the autonomous inquiry of novices can actually benefit the larger group as well. If such deliberation helps shape the intellectual character of those inquirers, and they are thereby made to be better epistemic agents, the broader community also benefits by being comprised of better epistemic agents. So, an individual's failed autonomous inquiry can also be valuable for society more broadly. This shows that value of type (iv) is attainable after all. ${ }^{46}$

In summary, autonomous deliberation can be successful or unsuccessful in terms of succeeding at figuring it out for yourself. Either way, there can be epistemic benefits for autonomous deliberators. In the good case, autonomous deliberators can attain understanding as well as a more secure epistemic position on the matter. In the bad case, autonomous deliberators can still come to understand the debate, gain unexpected epistemic rewards, and cultivate intellectual virtues such as intellectual humility.

\section{Words of caution}

While we have seen that autonomous deliberation can be epistemically valuable, none of the considerations above count against deference to the experts. The epistemic goods to

\footnotetext{
${ }^{44}$ This conclusion should not be exaggerated. The claim defended here is only that autonomous novice deliberation can cultivate intellectual virtues like intellectual humility. There may be other ways to cultivate these virtues, and I have not argued that autonomous novice deliberation is the best way to cultivate them. Nevertheless, that autonomous novice deliberation can do so, shows us how such deliberation can be epistemically valuable. In addition, the fact that autonomous deliberation can lead to developing intellectual virtues does not imply that it cannot also lead to developing intellectual vices. For instance, it could be that continued success in autonomous deliberation cultivates a kind of intellectual arrogance. Thanks to an anonymous reviewer for this point.

${ }^{45}$ The benefits of failed autonomous deliberation outlined here are not exclusive to failed deliberation. In successful autonomous deliberation subjects can also come to understand the debate, understand the answer to some other question, and develop intellectual virtues. The point of highlighting these benefits here is simply to note that even failed deliberation has its epistemic benefits. Thanks to an anonymous reviewer for noting this.

${ }^{46}$ In revisiting our reasons for skepticism for novice autonomous deliberation being valuable for a group, the reasons outlined above all concerned value of type (iii) rather than value of type (iv). As we now see, there is room for value of type (iv).
} 
be had by thinking for oneself can be obtained while still deferring to the experts. One can defer to expert opinion, and then try to work things out for oneself in the hopes of gaining understanding. Alternatively, one can think for oneself, and then consult expert opinion to ensure they landed on the correct answer, and revise if necessary. Autonomous deliberation does not entail that one is reasonable in believing the conclusion that they came to. If their conclusion conflicts with expert opinion (either by it being a different conclusion or there being no expert consensus on the matter), then the subject will not be justified in believing their conclusion. However, as we have seen, this does entail that they still cannot obtain other epistemic benefits from their autonomous deliberation. ${ }^{47}$ Deferring to experts remains the best route to finding the answers to our questions. None of the considerations above tell against deferring, rather they tell against mere deference, where mere deference entails that one does not also autonomously deliberate about the matter. By deferring we do our best to get at the truth, and by thinking for ourselves we can try to get even more (e.g. understanding, defeat management, developing intellectual virtue). ${ }^{48}$

The above considerations about the epistemic value of autonomous novice deliberation also do not entail that it is always a good thing to engage in such deliberation. For one thing, autonomous deliberation can end up leading you away from the truth. In some cases, the negative epistemic consequences of autonomous deliberation will outweigh the positive. To show that there can be positive epistemic outcomes is not to show that autonomous deliberation will always be (on balance) epistemically beneficial. In addition, autonomous deliberation can sometimes be epistemically inappropriate in and of itself. In some cases, an insistence to 'see things for oneself,' or at least an attempt to do so, exhibits a problematic lack of trust in others. For instance, if my partner tells me that the dogs were fed earlier in the day, and I refuse to believe it without first acquiring and appreciating the relevant first-order evidence for myself, then my autonomous inquiry exhibits an epistemic defect in me. If I need to gather and examine the evidence for myself, then I exhibit a problematic lack of trust in my partner and their ability to evaluate the relevant evidence.

When a speaker tells a hearer something, they have offered the hearer an invitation to trust them (Hinchman 2005: 565-8). ${ }^{49}$ When the hearer lacks a reason to distrust the speaker, a refusal to trust the speaker wrongs the speaker. In telling the hearer that $p$, the speaker has invited them to trust that they have sufficient evidence on the matter and that they are a competent evaluator of that evidence - they have vouched for the truth of what they have said. A refusal to trust such a speaker demonstrates doubts about the speaker's credibility or sincerity and is a rejection of their epistemic offerings. ${ }^{50}$ When these doubts are not justified, the speaker's invitation to trust has wrongly been rejected. So, in cases where the hearer lacks evidence relevant to $p$, and their

\footnotetext{
${ }^{47}$ This is borne out in teaching philosophy. We want our students to think for themselves about complex and controversial philosophical ideas. Doing so has a number of benefits for students, but it does not entail that they are reasonable in believing whichever conclusion they settle on. This is one lesson from the literature on the epistemic significance of disagreement.

${ }^{48}$ Returning to the earlier baking analogy, the recommendation here is to (at least sometimes) try out the recipe for oneself, while still relying on Martha Stewart finished dessert to use as your submission. In doing so, one can gain benefits that could not be had by merely relying on Martha's dessert alone. Thanks to an anonymous reviewer for pressing me to make this compatibility more explicit.

${ }^{49}$ Moran (2006: 283) echoes this same sentiment and sees the speaker as offering a 'guarantee for this truth' in what they tell the hearer. Along these lines, Goldberg (2020: 97) argues that the speaker then 'owes it' to the testifier to respond to what she tells her in line with the speaker's epistemic credentials on the matter. In such cases, if the hearer refuses to take the speaker's word for it, they wrong the speaker.

${ }^{50}$ See Hazlett (2017: 42). Hazlett argues, to refuse such testimony is to insult the speaker.
} 
evidence supports that the speaker is credible regarding $p$, the hearer's insistence on getting the speaker's evidence before believing $\mathrm{p}$ will amount to a refusal of the speaker's offer to trust them. ${ }^{51}$ To autonomously deliberate about the matter by insisting on getting the speaker's reasons for believing $p$ is to show a lack of trust in the speaker's ability to evaluate their evidence (contrary to the hearer's evidence of their credibility) - it is to treat them as insincere or incompetent. Such a refusal to take the speaker's word for it can be problematic and harmful. So, in some cases, autonomous deliberation is epistemically defective. $^{52}$

A special case of this occurs when autonomous deliberation exhibits epistemic injustice. If a credible colleague reports to me that she has been sexually harassed in the workplace, and rather than simply trusting her, I rely on, and equally weigh, my own experiences with the perpetrator in question, then my autonomous deliberation on the matter perpetuates epistemic injustice against my colleague. Following Fricker (2007: 20) we can understand epistemic injustice as "a kind of injustice in which someone is wronged specifically in her capacity as a knower" which includes her capacity as an informant.

Why might autonomous deliberation perpetuate epistemic injustice? The kind of epistemic injustice exhibited in such cases is what Fricker has termed testimonial injustice.' According to Fricker, "the speaker sustains a testimonial injustice if and only if she receives a credibility deficit owing to identity prejudice in the hearer" (Fricker 2007: 28). So, when someone refuses the testimony of another due to their prejudice, they commit an epistemic injustice toward the speaker. Such a dismissal is (epistemically) unfair to the speaker and can happen with autonomous deliberation. Similarly, when an individual is treated as a mere source of information to be evaluated, rather than an informant (to be believed), due to the prejudices of the hearer, the speaker has been harmed in an epistemically unjust way.

What all of this shows is that while autonomous deliberation can be epistemically valuable, it can also be epistemically harmful. When an individual fails to trust what someone tells them, despite having good reason to do so, they can harm that speaker and thereby commit an epistemic injustice.

\section{The intellectual virtue of epistemic autonomy}

These considerations concerning the potential epistemic benefits and harms of autonomous deliberation indicate that there is an intellectual virtue in the neighborhood. The intellectual virtue of epistemic autonomy is something like the disposition to think for yourself about the right things, to think about them in the right way, and for the right reasons (with proper motivation). As an intellectual virtue, these dispositions would need to be motivated by the subject's love of truth, or their desire for epistemic goods. This suggests the following initial sketch of the virtue of epistemic autonomy:

\footnotetext{
${ }^{51}$ Requesting the speaker's reasons for believing $\mathrm{p}$ may be part of the hearer's quest for understanding and motivated by their love of truth. Such requests are not defective. It is important that in our case above the hearer insisted on getting the speaker's reasons prior to believing the speaker. The quest for understanding happens after the hearer already believes the speaker.

${ }^{52}$ These considerations may lead one to believe that you should never conduct autonomous inquiry when someone has already told you the answer to your question. However, some actions require a very high epistemic standard to be met. If you are contemplating whether to undergo a serious medical procedure, it is reasonable to demand a greater degree of justification before proceeding. It is reasonable to get a second opinion. Such extended inquiry does not wrong the testifier (the first doctor) since the relevant epistemic standards are higher. The epistemic standards here are not simply the epistemic standards for justified belief, but the epistemic standards for a rational high stakes action. In such cases, it will be rational to believe the first doctor, but also to gather more evidence so as to gain a greater degree of justification.
} 
The character virtue of epistemic autonomy characteristically involves dispositions (1) [cognitive] to make good judgments about how, and when, to rely on your own thinking, as well as how, and when, to rely on the thinking of others, (2) [behavioral] to conduct their inquiry in line with those judgments, and (3) [motivational] to do so because one loves the truth and appropriately cares about epistemic goods. ${ }^{53}$

The epistemically autonomous person manages their intellectual life well. They rely on the insights of others, while taking care to develop their own intellectual character when it is appropriate. Such individuals exhibit a healthy intellectual interdependence. Note that such virtue requires that one undergoes autonomous inquiry and that one manages which projects they take on, and when, well.

Someone who has the virtue of epistemic autonomy, does that well. Autonomous deliberation can also have proper or improper motivations. When virtuously exercised, it is motivated by a love of truth, but autonomous deliberation can also be motivated by an unhealthy suspicion of other people, an overestimation of one's own intellectual abilities, a need to prove someone else wrong, and so forth. When virtuously exercised, epistemic autonomy is motivated by a love of truth and a desire for epistemic goods. While more work needs to be done in analyzing and assessing the epistemic value of such an intellectual trait, we have seen good reason to think that there is such a virtue.

\section{Conclusion}

In this paper I have set out to answer the question of why novices should think for themselves about some question when they could instead merely defer to the experts. What we have seen is that autonomous deliberation can be epistemically valuable for inquirers both when it succeeds as well as when it fails. When it succeeds, autonomous deliberation can bring understanding as well as an ability to manage new information. When it fails, autonomous deliberation can nevertheless allow inquirers to understand a debate by getting a feel for 'the lay of the land'. Further, we don't always know where our inquiry will lead. Sometimes, even though our inquiry into one particular question fails, the inquiry nevertheless succeeds in answering some other question, and thus provides us with unforeseen epistemic rewards. Finally, failed autonomous deliberation can cultivate intellectual virtues such as intellectual humility. Since intellectual humility is an intellectual virtue, it is epistemically valuable. Failed autonomous deliberation then is also epistemically valuable insofar as it cultivates this virtue.

So, there are reasons why you should think for yourself. However, these reasons to think for yourself are not also reasons not to defer. We have seen that autonomous deliberation and deference are compatible. Further, we have seen that there are limits to the value of autonomous deliberation - that autonomous deliberation can sometimes have net negative epistemic consequences, and that it can sometimes be epistemically harmful in and of itself. Whether one should autonomously deliberate will depend on how all of these reasons stack up in any particular case, but we have come to see the reasons relevant to this issue. These considerations have led us to an initial sketch of the virtue of epistemic autonomy. Individuals who possess this virtue know when, and how, to deliberate autonomously, and they do so motivated by a love of the truth and appropriate care for epistemic goods. ${ }^{54}$

\footnotetext{
${ }^{53}$ For a fuller explication and defense of this account of the virtue of epistemic autonomy, as well as how it differs from other accounts of this intellectual virtue, see Matheson (2021).

${ }^{54}$ I would like to thank Heather Battaly, James Beebe, Valerie Joly Chock, Finnur Dellsén, Robert Gressis, Nathan King, Ted Poston, Joshua Smith, Sarah Wright, participants at the 2020 Southeastern Epistemology
} 


\section{References}

Baehr J. (2011). The Inquiring Mind. New York, NY: Oxford University Press.

Boyd K. (2017). 'Testifying Understanding.' Episteme 14, 103-27.

Cholbi M. (2007). 'Moral Expertise and the Credentials Problem.' Ethical Theory and Moral Practice 10(4), 323-334.

Coady C.A.J. (2002). 'Testimony and Intellectual Autonomy.' Studies in History and Philosophy of Science Part A 33(2), 355-72.

Collins H. and Evans R. (2007). Rethinking Expertise. Chicago, IL: Chicago University Press.

Dellsén F. (2018). 'When Expert Disagreement Supports the Consensus.' Australasian Journal of Philosophy 96(1), 142-56.

Dellsén F. (2020). 'The Epistemic Value of Expert Autonomy.' Philosophy and Phenomenological Research 100(2), 344-61.

Dellsén F. (2021). 'We Owe it to Others to Think for Ourselves.' In J. Matheson and K. Lougheed (eds), Epistemic Autonomy, pp. 306-22. New York, NY: Routledge.

de Regt H.W. (2009). 'The Epistemic Value of Understanding.' Philosophy of Science 76(5), 585-97.

Ebels-Duggan K. (2014). 'Autonomy as Intellectual Virtue.' In H. Brighouse and M. MacPherson (eds), The Aims of Higher Education, pp. 74-90. Chicago, IL: University of Chicago Press.

Elgin C.Z. (2013). 'Epistemic Agency.' Theory and Research in Education 11(2), 135-52.

Elgin C.Z. (2017). True Enough. Cambridge, MA: MIT Press.

Encabo J.V. (2008). 'Epistemic Merit, Autonomy, and Testimony.' Theoria: An International Journal for Theory, History and Foundations of Science 23(61), 45-56.

Fricker E. (2006). 'Testimony and Epistemic Autonomy.' In J. Lackey and E. Sosa (eds), The Epistemology of Testimony, pp. 225-351. Oxford: Oxford University Press.

Fricker M. (2007). Epistemic Injustice: Power and the Ethics of Knowing. Oxford: Oxford University Press.

Fumerton R. (2010). 'You Can't Trust a Philosopher.' In R. Feldman and T. Warfield (eds), Disagreement, pp. 91-110. New York, NY: Oxford University Press.

Gardiner G. (2012). 'Understanding, Integration, and Epistemic Value.' Acta Analytica 27(2), 163-81.

Goldberg S. (2013). 'Epistemic Dependence in Testimonial Belief, in the Classroom and Beyond.' Journal of Philosophy of Education 47(2), 168-186.

Goldberg S. (2020). Conversational Pressure. Oxford: Oxford University Press.

Goldberg S. (2021). 'Epistemic Autonomy and the Right to be Confident.' In J. Matheson and K. Lougheed (eds), Epistemic Autonomy, pp. 288-305. New York, NY: Routledge.

Goldman A. (2001). 'Experts: Which Ones Should You Trust?' Philosophy and Phenomenological Research 63, 85-110.

Gordon E.C. (2012). 'Is There Propositional Understanding?' Logos \& Episteme 3, 181-92.

Grasswick H. (2018). 'Epistemic Autonomy in a Social World of Knowing.' In H. Battaly (ed.), The Routledge Handbook of Virtue Epistemology, pp. 196-208. New York, NY: Routledge.

Grimm S. (2010). 'The Goal of Understanding.' Studies in the History and Philosophy of Science 41(4), 33744.

Grimm S. (2011). 'Understanding.' In S. Bernecker and D. Pritchard (eds), The Routledge Companion to Epistemology, pp. 84-94. New York, NY: Routledge.

Grundmann T. (2021). 'Facing Epistemic Authorities: Where Democratic Ideals and Critical Thinking Mislead Cognition.' In S. Bernecker, A. Floweree and T. Grundmann (eds), The Epistemology of Fake News, pp. 134-55. Oxford: Oxford University Press.

Hardwig J. (1985). 'Epistemic Dependence.' Journal of Philosophy 82, 335-49.

Hazlett A. (2016). 'The Social Value of Non-Deferential Belief.' Australasian Journal of Philosophy 94, 131-51.

Hazlett A. (2017). 'On the Special Insult of Refusing Testimony.' Philosophical Explorations 20, 31-51.

Hills A. (2009). 'Moral Testimony and Moral Epistemology.' Ethics 120, 94-127.

Hills A. (2013). 'Moral Testimony.' Philosophy Compass 8, 552-9.

Hinchman T. (2005). 'Telling as Inviting to Trust.' Philosophy and Phenomenological Research 70(3), 562-87.

Huemer M. (2005). 'Is Critical Thinking Epistemically Responsible?' Metaphilosophy 36, 522-31.

King N. (2020). The Excellent Mind: Intellectual Virtue for the Everyday Life. Oxford: Oxford University Press.

Conference, and two anonymous referees for their helpful feedback on this paper. This publication was made possible through the support of a grant from the John Templeton Foundation (ID\# 61802). The opinions expressed in this publication are those of the author(s) and do not necessarily reflect the views of the John Templeton Foundation. 
Kitcher P. (1993). The Advancement of Science: Science without Legend, Objectivity without Illusions. New York, NY: Oxford University Press.

Kvanvig J. (2003). The Value of Knowledge and the Pursuit of Understanding. New York, NY: Cambridge University Press.

Lane M. (2014). 'When the Experts are Uncertain: Scientific Knowledge and the Ethics of Democratic Judgment.' Episteme 11, 97-118.

Levy N. (2007). 'Radically Socialized Epistemology.' Episteme 4(2), 181-92.

Matheson J. (2015). The Epistemic Significance of Disagreement. London: Palgrave.

Matheson J. (2021). 'The Virtue of Epistemic Autonomy.' In J. Matheson and K. Lougheed (eds), Epistemic Autonomy, pp. 173-94. New York, NY: Routledge.

Matheson J., McElreath S. and Nobis N. (2018). 'Moral Experts, Deference \& Disagreement.' In J. Watson and L. Guidry-Grimes (eds), Moral Expertise: New Essays from Theoretical and Clinical Perspectives, pp. 87-105. New York, NY: Springer.

McGrath S. (2009). 'The Puzzle of Pure Moral Deference.' Philosophical Perspectives 23(1), 321-44.

Medina J. (2012). The Epistemology of Resistance: Gender and Racial Oppression, Epistemic Injustice, and Resistant Imaginations. New York, NY: Oxford University Press.

Millgram E. (2015). The Great Endarkenment: Philosophy for An Age of Hyperspecialization. New York, NY: Oxford University Press.

Moran R. (2006). 'Getting Told and Being Believed.' In J. Lackey and E. Sosa (eds), The Epistemology of Testimony, pp. 272-306. Oxford: Oxford University Press.

Nedelsky J. (1989). 'Reconceiving Autonomy: Sources, Thoughts and Possibilities.' Yale Journal of Law and Feminism 1, 7-36.

Nickel P. (2001). 'Moral Testimony and its Authority.' Ethical Theory and Moral Practice 4(3), 253-66.

Nguyen C.T. (2018). 'Expertise and the Fragmentation of Intellectual Autonomy.' Philosophical Inquiries 6 (2), 107-24.

Nguyen C.T. (2020). 'Cognitive Islands and Runaway Echo Chambers: Problems for Epistemic Dependence on Experts.' Synthese 197, 2803-21.

Nussbaum M. (2017). Not for Profit: Why Democracy Needs the Humanities (Updated Edition). Princeton, NJ: Princeton University Press.

Pritchard D. (2009). 'Knowledge, Understanding and Epistemic Value.' Royal Institute of Philosophy Supplements 64, 19-43.

Pritchard D. (2016). 'Seeing It for Oneself: Perceptual Knowledge, Understanding, and Intellectual Autonomy.' Episteme 13(1), 29-42.

Raz J. (1988). The Morality of Freedom. Oxford: Clarendon Press.

Roberts R.C. and Wood W.J. (2010). Intellectual Virtues: An Essay in Regulative Epistemology. Oxford: Oxford University Press.

Russell B. (2016). The Problems of Philosophy. CreateSpace Independent Publishing Platform; 1st edition.

Westlund A. (2012). 'Autonomy in Relation.' In S.L. Crasnow and A.M. Superson (eds), Out from the Shadows: Analytical Feminist Contributions to Traditional Philosophy, pp. 59-81. New York, NY: Oxford University Press.

Whitcomb D., Battaly H., Baehr J. and Howard-Snyder D. (2017). 'Intellectual Humility: Owning our Limitations.' Philosophy and Phenomenological Research 94(3), 509-39.

Zagzebski L. (2007). 'Ethical and Epistemic Egoism and the Ideal of Autonomy.' Episteme 4, 252-63.

Zagzebski L. (2008). On Epistemology. Belmont, CA: Wadsworth.

Zagzebski L. (2012). Epistemic Authority: A Theory of Trust, Authority, and Autonomy in Belief. New York, NY: Oxford University Press.

Jonathan Matheson is a Professor of Philosophy at the University of North Florida. He is the author of The Epistemic Significance of Disagreement (Palgrave), co-editor of The Ethics of Belief: Individual and Social (Oxford), and co-editor of Epistemic Autonomy (Routledge).

Cite this article: Matheson J (2022). Why Think for Yourself? Episteme 1-19. https://doi.org/10.1017/ epi.2021.49 